\title{
Quantification of the impact of segmentectomy on pulmonary function by perfusion single-photon-emission computed tomography and multidetector computed tomography
}

\author{
Kentaro Yoshimoto, MD, ${ }^{\text {a }}$ Hiroaki Nomori, MD, PhD, ${ }^{a}$ Takeshi Mori, MD, PhD, ${ }^{\text {a }}$ Hironori Kobayashi, MD, PhD, ${ }^{a}$ \\ Yasuomi Ohba, MD, ${ }^{\mathrm{a}}$ Hidekatsu Shibata, MD, ${ }^{\mathrm{a}}$ Kuniyuki Tashiro, MD, ${ }^{\mathrm{b}}$ Shinya Shiraishi, MD, PhD, ${ }^{\mathrm{b}}$ and \\ Toshiaki Kobayashi, $\mathrm{MD}, \mathrm{PhD}^{\mathrm{c}}$
}

\begin{abstract}
Objective: The impact of segmentectomy for preservation of pulmonary function was quantified by using a coregistered perfusion single-photon-emission computed tomography and multidetector computed tomography (SPECT/CT).
\end{abstract}

\begin{abstract}
Methods: Pulmonary function tests and perfusion SPECT/CT were conducted before and after segmentectomy in 56 patients. Actual values of forced expiratory volume in 1 second $\left(\mathrm{FEV}_{1}\right)$ after segmentectomy were compared with the $\mathrm{FEV}_{1}$ after virtual lobectomy, which was calculated by SPECT/CT. The preoperative and postoperative $\mathrm{FEV}_{1}$ of each lobe that had undergone segmentectomy was measured by SPECT/CT.

Results: The mean percent of $\mathrm{FEV}_{1}$ preserved after segmentectomy was significantly higher than the value after virtual lobectomy $(88 \% \pm 9 \%$ vs $77 \% \pm 7 \% ; P<.001)$. Whereas the mean value of the preoperative $\mathrm{FEV}_{1}$ of each lobe that was undergoing segmentectomy was $0.51 \pm 0.21 \mathrm{~L}$, segmentectomy could preserve $41 \% \pm 24 \%$ of it. The $\mathrm{FEV}_{1}$ of each lobe after the resection of more than three segments $(\mathrm{n}=4)$ was preserved in $17 \% \pm 12 \%$ of the preoperative values, which was significantly less than $49 \% \pm 23 \%$ and $35 \% \pm 22 \%$ after the resection of one $(\mathrm{n}=29)$ and two $(\mathrm{n}=23)$ segments $\left(P=.02\right.$ and .08 , respectively). The $\mathrm{FEV}_{1}$ of the left upper lobe after the upper division segmentectomy $(\mathrm{n}=8)$ was preserved in $21 \% \pm 11 \%$ of the preoperative values, which was significantly less than $35 \% \pm 12 \%$ after the lingular segmentectomy $(\mathrm{n}=7)(P=.03)$.
\end{abstract}

Conclusion: Segmentectomy can preserve the pulmonary function more significantly than lobectomy, except for the resection of more than three segments or the left upper division segmentectomy.

Several recent studies of segmentectomy for lung cancer suggest that segmentectomy can produce cure rates equivalent to those obtained after lobectomy in patients with T1 N0 non-small cell lung cancer (NSCLC) ${ }^{1-5}$ However, controversies for preservation of pulmonary function remain because of the strong impact from the results of only one randomized controlled trial by the Lung Cancer Study Group in 1995, which showed little advantage in postoperative pulmonary function after segmentectomy. ${ }^{6}$ Although the previous reports compared the data of postoperative pulmonary function testing between lobectomy and segmentectomy, ${ }^{6-9}$ the pulmonary function of each lobe that had been subjected to segmentectomy has not been examined.

The recent development of a co-registered single-photonemission computed tomography (SPECT) and computed tomography (CT) imaging (SPECT/CT) can show the

From the Departments of Thoracic Surgery ${ }^{\mathrm{a}}$ and Diagnostic Radiology, ${ }^{\mathrm{b}}$ Graduate School of Medical Sciences, Kumamoto University, Kumamoto, Japan, and the Department of Assistive Diagnostic Technology, ${ }^{\mathrm{c}}$ National Cancer Center Hospital, Tokyo, Japan.

Received for publication Feb 13, 2008; revisions received Oct 1, 2008; accepted for publication Oct 25, 2008

Address for reprints: Hiroaki Nomori, MD, PhD, Department of Thoracic Surgery, Graduate School of Medical Sciences, Kumamoto University, 1-1-1 Honjo,

Kumamoto 860-8556, Japan (E-mail: hnomori@qk9.so-net.ne.jp).

J Thorac Cardiovasc Surg 2009; 137:1200-5

$0022-5223 / \$ 36.00$

Copyright (c) 2009 by The American Association for Thoracic Surgery doi: $10.1016 /$ j.jtcvs.2008.10.028 anatomy of the lung on perfusion SPECT images, enabling the measurement of pulmonary function of each lobe. ${ }^{10}$ Therefore, the preservation of pulmonary function of each lobe after segmentectomy would be measurable by the perfusion SPECT/CT. Since April 2005, we have conducted a prospective study of segmentectomy for C-T1 N0 M0 NSCLC. ${ }^{11}$ To evaluate the usefulness of segmentectomy for preservation of postoperative pulmonary function in the present study, we compared pulmonary function between segmentectomy and virtual lobectomy and also used a perfusion SPECT/CT to measure the preserved pulmonary function of each lobe that had undergone segmentectomy.

\section{PATIENTS AND METHODS Eligibility}

The study for examining perfusion scintigraphy with SPECT/CT in patients undergoing major lung resection was approved by the Ethics Committee of Kumamoto University Hospital in April 2005. Informed consent was obtained from all patients after the costs and benefits of the study had been discussed.

\section{Patients}

Between August 2005 and June 2007, 96 patients had undergone segmentectomy for NSCLC $(n=85)$, metastatic lung cancer $(n=9)$, and other diseases $(n=2)$. Of the 96 patients, 15 were excluded because they had undergone additional resections for other lesions. Twenty-five patients were also excluded because perfusion SPECT/CT was not conducted both before and after segmentectomy. As a result, 56 patients were enrolled in 


$$
\begin{aligned}
& \text { Abbreviations and Acronyms } \\
& \mathrm{CT}=\text { computed tomography } \\
& \text { DICOM = } \text { Digital Imaging and } \\
& \text { Communications in Medicine } \\
& \mathrm{FEV}_{1}= \text { forced expiratory volume in } 1 \text { second } \\
& \mathrm{LUL}= \text { left upper lobe } \\
& \mathrm{NSCLC}= \text { non-small cell lung cancer } \\
& \mathrm{RI}= \text { radioisotope } \\
& \mathrm{RLL}= \text { right lower lobe } \\
& \mathrm{RUL}= \text { right upper lobe } \\
& \text { SPECT }= \text { single-photon-emission computed } \\
& \text { tomography }
\end{aligned}
$$

the present study; they were examined with pulmonary function tests and perfusion SPECT/CT before and after segmentectomy (Table 1). One segment was resected in 29 patients, two segments in 23 patients, three segments in 2 patients, and four segments in 2 patients, with a mean number of $1.6 \pm 0.7$ segments per patient. Table 2 shows the sites of segmentectomy in each lobe.

\section{Pulmonary Function Tests}

Vital capacity, forced vital capacity, and forced expiratory volume in 1 second $\left(\mathrm{FEV}_{1}\right)$ were measured with the patient in a seated position using a dry rolling-seal spirometer (CHESTAC-9800DN; CHEST Inc, Tokyo, Japan) according to American Thoracic Society standards. ${ }^{12}$

\section{SPECT/CT}

Lung perfusion scintigraphy images were obtained by a SPECT/CT system. This system was composed of a commercially available gantry-free SPECT with dual-head detectors (Skylight; ADAC Laboratories, Milpitas, Calif) and an 8-multidetector-row CT scanner (Light-Speed Ultra Instrument; General Electric, Milwaukee, Wis). The two instruments were juxtaposed so that the CT table carrying the patient could be moved directly into the SPECT scanner before CT scanning. As a result, each patient was identically positioned for SPECT and CT imaging.

Each $185 \mathrm{MBq}$ of ${ }^{99 \mathrm{~m}} \mathrm{Tc}$-macroaggregated human serum albumin (Daiichi Radioisotope Laboratories, Ltd, Tokyo, Japan) was administered intravenously with the patient first in the supine then in the prone position to make the albumin distribute uniformly.

SPECT data acquisition was performed with a vertex ultra-high resolution parallel-hole collimator. A 360-SPECT scan was acquired and was followed by CT scanning. Reconstructive CT images were processed into Digital Imaging and Communications in Medicine (DICOM) data and then transferred to Pegasys (ADAC Laboratories, Milpitas, Calif), which is a workstation for SPECT processing. One lumen of a 3-way stopcock (inner diameter $4 \mathrm{~mm}$, length $10 \mathrm{~mm}$ ) containing an aqueous solution of $99 \mathrm{~m}$ technetium pertechnetate $\left({ }^{99 \mathrm{~m}} \mathrm{TcO}_{4}{ }^{-}\right)$and a contrast medium was used as an external fiducial marker. To obtain a precise record of both images, we fixed external fiducial markers to the common platform for SPECT and CT imaging. The two scans were performed sequentially. The SPECT images were manually fused with the CT images by aligning the external fiducial markers of the two images on the workstation. Transaxial, coronal, and sagittal sections of SPECT and CT images were manually fused with each other to obtain the best matching images on a workstation (AZE Virtual Place; AZE Co Ltd, Tokyo, Japan).

Postoperative SPECT/CT was conducted with the pulmonary function test more than 6 months after surgery (median 12 months; range 6-24 months).
TABLE 1. Patients' characteristics

\begin{tabular}{lc}
\hline \multicolumn{1}{c}{ Mean age (y) (range) } & $\mathbf{7 0 \pm 9}(\mathbf{3 2 - 8 2})$ \\
\hline Sex & 25 \\
Male & 31 \\
Female & $2.2 \pm 0.6$ \\
Mean FEV $_{1}(\mathrm{~L})$ & $74 \pm 9$ \\
Mean FEV $_{1} / \mathrm{FVC}(\%)$ & $3.0 \pm 0.8$ \\
Mean FVC (L) & $109 \pm 14$ \\
Mean \%FVC (\%) & \\
Lobe undergoing segmentectomy & 9 \\
Right upper lobe & 16 \\
Right lower lobe & 22 \\
Left upper lobe & 9 \\
Left lower lobe & \\
No. of resected segments & 29 \\
1 & 23 \\
2 & 2 \\
3 & 2 \\
4 & $1.8 \pm 0.7(0.8-4.4)$ \\
Mean tumor size (cm) (range) & 33 \\
$0-2$ & 21 \\
$2-3$ & 2 \\
$>3$ &
\end{tabular}

\section{Measurement of $\mathrm{FEV}_{1}$ After Virtual Lobectomy}

The postoperative $\mathrm{FEV}_{1}$ after virtual lobectomy was predicted by SPECT/CT. The objective lobe was traced on the CT image with a region of interest, making the SPECT image after lobectomy (Figure 1). $\mathrm{FEV}_{1}$ after virtual lobectomy was predicted according to the following formula:

$\mathrm{FEV}_{1}$ after virtual lobectomy $=$ Preoperative $\mathrm{FEV}_{1} \times(\mathrm{RI}$ counts of the whole lung after virtual lobectomy/RI counts of the whole lung before surgery), where RI is radioisotope.

TABLE 2. Sites of segmentectomy

\begin{tabular}{lllc}
\hline \multicolumn{1}{c}{ Segment } & No. of patients & \multicolumn{1}{c}{ Segment } & No. of patients \\
\hline RUL $(\mathrm{n}=9)$ & & LUL $(\mathrm{n}=22)$ & \\
S1 & 1 & S $1+2$ & 3 \\
S2 & 3 & S3 & 3 \\
S3 & 4 & S1+2, 3 & 8 \\
S3, 2a & 1 & S4, 5 & 7 \\
& & S3, 1+2a & 1 \\
RLL $(\mathrm{n}=16)$ & & LLL $(\mathrm{n}=9)$ & \\
S6 & 6 & S6 & 2 \\
S7, 8 & 1 & S8 & 1 \\
S8 & 3 & S8, 9 & 3 \\
S9 & 1 & S9, 10 & 2 \\
S9, 10 & 1 & S8, 9, 10 & 1 \\
S7, 8, 9, 10 & 2 & & \\
S10 & 1 & & \\
S6, 9, 10 & 1 & & \\
Total & 25 & & \\
\hline
\end{tabular}

$R U L$, Right upper lobe; $R L L$, right lower lobe; $L U L$, left upper lobe, $L L L$, left lower lobe; $S$, segment. Right upper lobe: $S 1$, apical; $S 2$, anterior; $S 3$, posterior. Right lower lobe: $S 6$, apical; $S 7$, medial; $S 8$, anterior; $S 9$, lateral; $S 10$, posterior. Left upper lobe: $S 1+2$, apical posterior; $S 3$, apical anterior; $S 4$, superior lingular; $S 5$, inferior lingular. Left lower lobe: $S 6$, apical; $S 8$, anterior; $S 9$, lateral; $S 10$, posterior. 

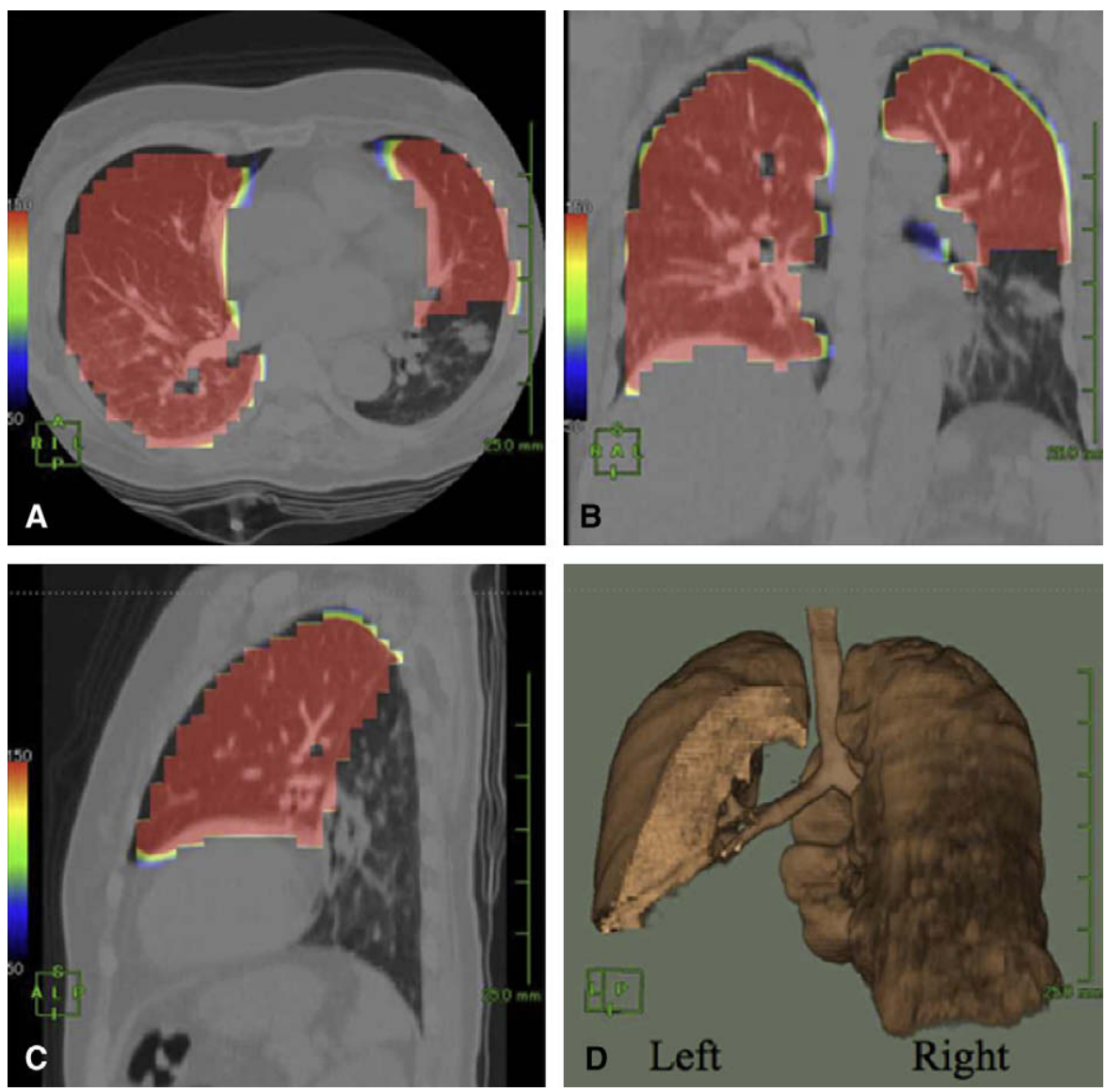

FIGURE 1. Virtual lobectomy of the left lower lobe on single-photon-emission computed tomography (SPECT) in a patient. A, Axial. B, Coronal. C, Sagittal. $\mathrm{D}$, Three-dimensional imaging.

\section{Measurement of Pulmonary Function of Each Lobe}

Images of the lobe before segmentectomy and of the remaining lobe after segmentectomy were traced on the CT image with region of interest, of which RI was counted on the SPECT image (Figure 2). The FEV 1 of the objective lobe before and after segmentectomy was measured from the preoperative or postoperative SPECT/CT according to the following formula:

$\mathrm{FEV}_{1}$ of the lobe before or after segmentectomy $=$ Preoperative or postoperative $\mathrm{FEV}_{1} \times(\mathrm{RI}$ counts of the lobe/RI counts of the whole lung).

\section{Statistical Analysis}

The paired $t$ test was used to compare the pulmonary function before and after virtual lobectomy by using SPSS software (SPSS, Inc, Chicago, Ill). The Student $t$ test was used to compare the $\mathrm{FEV}_{1}$ of the remaining lobe among the number of resected segments and the sites of the lobe. All values in the text and table are given as mean $\pm \mathrm{SD}$.

\section{RESULTS}

There were no postoperative major complications after segmentectomy in any of the patients. Figure 3 shows the actual values of $\mathrm{FEV}_{1}$ before and after segmentectomy and the predicted values after virtual lobectomy. The mean values of $\mathrm{FEV}_{1}$ before and after segmentectomy were $2.2 \pm 0.6$ and $1.9 \pm 0.5 \mathrm{~L}$, respectively, of which mean percent of $\mathrm{FEV}_{1}$ preserved was $88 \% \pm 9 \%$. The mean value of the predicted $\mathrm{FEV}_{1}$ after virtual lobectomy was $1.6 \pm 0.4 \mathrm{~L}$, of which mean percent of $\mathrm{FEV}_{1}$ preserved was $77 \% \pm 7 \%$. The postoperative $\mathrm{FEV}_{1}$ after segmentectomy was significantly higher than that after virtual lobectomy $(P<.001)$.

Figure 4 shows the $\mathrm{FEV}_{1}$ of each lobe that had undergone segmentectomy before and after surgery. The mean values of $\mathrm{FEV}_{1}$ of each lobe before and after segmentectomy were $0.51 \pm 0.21$ and $0.21 \pm 0.15 \mathrm{~L}$, respectively. The segmentectomy preserved $41 \% \pm 24 \%$ of the preoperative $\mathrm{FEV}_{1}$ of each lobe.

Table 3 shows the $\mathrm{FEV}_{1}$ of each lobe before and after segmentectomy according to the number of resected segments. Whereas the resections of one and two segments preserved $49 \% \pm 23 \%$ and $35 \% \pm 22 \%$ of preoperative $\mathrm{FEV}_{1}$ of each lobe, respectively, that of three or four segments preserved only $17 \% \pm 12 \%$. The mean percent of the preserved $\mathrm{FEV}_{1}$ with the resections of one and two segments was higher than that with the resection of three or four segments $(P=.02$ and .08 , respectively), whereas there was no significant difference between the resection of one and two segments. 

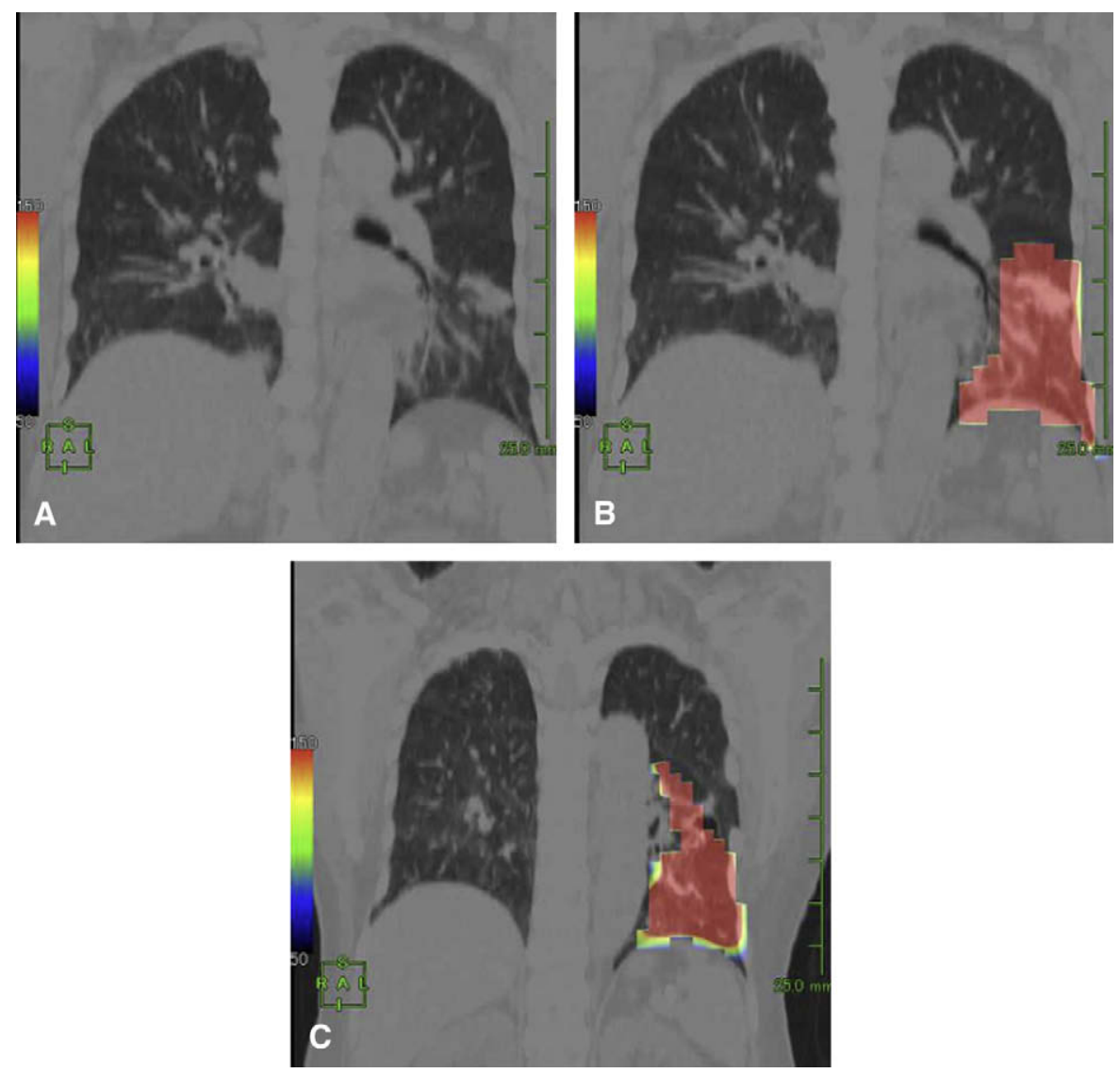

FIGURE 2. A, Coronal image of CT before surgery, showing a lung cancer in the anterior segment of the left lower lobe. B, Coronal image of the perfusion SPECT/CT of the left lower lobe before segmentectomy. C, Coronal image of the perfusion SPECT/CT of the remaining left lower lobe after segmentectomy.

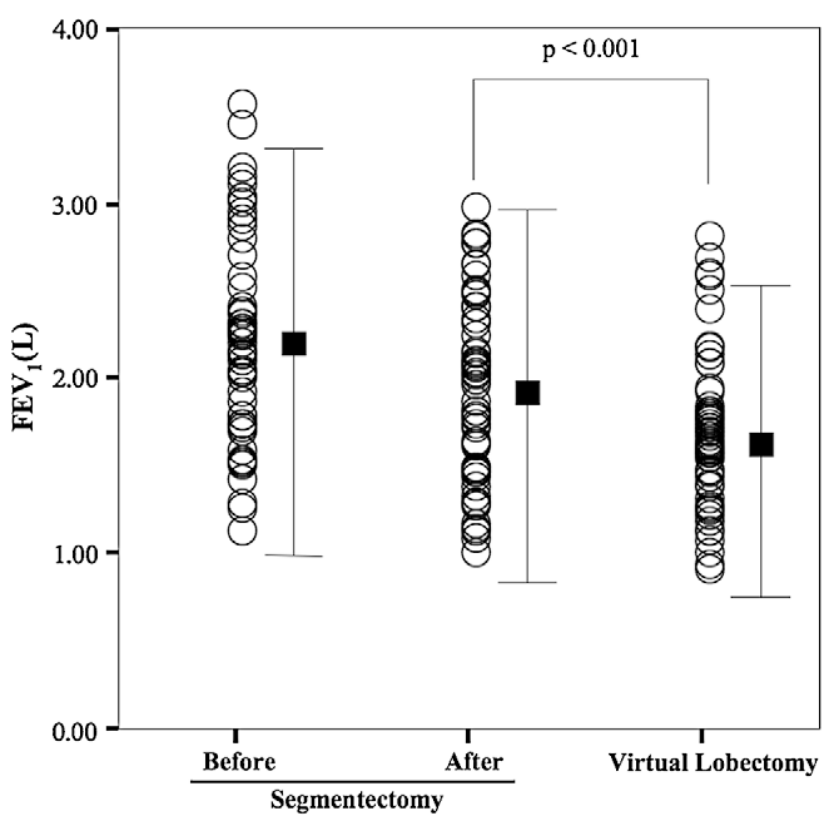

FIGURE 3. Measured forced expiratory volume in 1 second $\left(F E V_{1}\right)$ before and after segmentectomy and predicted value after virtual lobectomy.

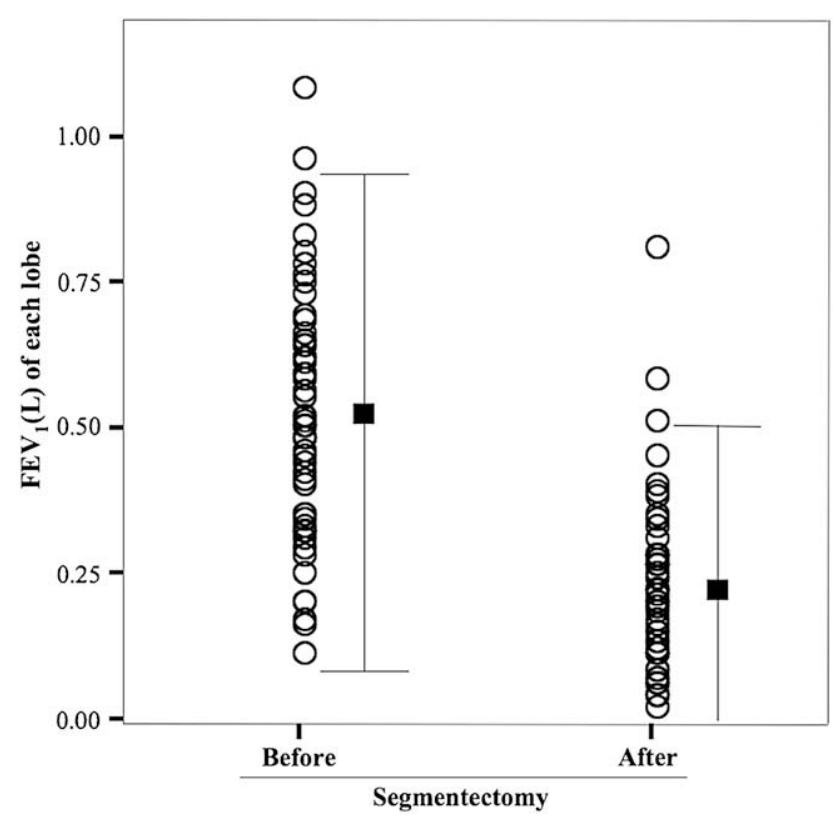

FIGURE 4. Forced expiratory volume in 1 second $\left(F E V_{l}\right)$ of each lobe before and after segmentectomy measured by perfusion SPECT/CT. 
TABLE 3. Forced expiratory volume in 1 second of the lobe before and after segmentectomy

\begin{tabular}{lcccc}
\hline & & \multicolumn{2}{c}{ Mean FEV $_{\mathbf{1}}$ of the lobe $(\mathbf{L})$} & \\
\cline { 3 - 4 } $\begin{array}{l}\text { No. of resected } \\
\text { segments }\end{array}$ & $\begin{array}{c}\text { No. of } \\
\text { patients }\end{array}$ & Before & After & $\begin{array}{c}\text { After/before } \\
(\%)\end{array}$ \\
\hline 1 & 29 & $0.52 \pm 0.21$ & $0.25 \pm 0.15$ & $49 \pm 23$ \\
2 & 23 & $0.54 \pm 0.21$ & $0.19 \pm 0.13$ & $35 \pm 22$ \\
3 or 4 & 4 & $0.32 \pm 0.15$ & $0.06 \pm 0.06$ & $17 \pm 12$ \\
\hline
\end{tabular}

$F E V_{l}$, Forced expiratory volume in 1 second.

Table 4 shows the $\mathrm{FEV}_{1}$ of the left upper lobe (LUL) before and after segmentectomy in 8 patients who had undergone upper division segmentectomy (the resection of apical posterior and apical anterior segments) and 7 patients who had undergone lingular segmentectomy (the resection of superior lingular and inferior lingular segments). The mean percent of $\mathrm{FEV}_{1}$ of the LUL after the upper division segmentectomy was $21 \% \pm 11 \%$ of the preoperative value, which was significantly lower than $35 \% \pm 12 \%$ after the lingular segmentectomy $(P=.03)$. There was no difference in the mean percent of $\mathrm{FEV}_{1}$ of the remaining lobe between the upper division segmentectomy and resections of more than three segments $(P=.54)$.

Table 5 shows the $\mathrm{FEV}_{1}$ of the lobe that had undergone segmentectomy before and after segmentectomy in each lobe. Although there was no significant difference in the number of resected segments among each lobe, the mean percent of $\mathrm{FEV}_{1}$ after segmentectomy in the right lower lobe (RLL) was $61 \% \pm 30 \%$ of the preoperative value, which was significantly higher than $34 \% \pm 13 \%$ and $32 \% \pm 14 \%$ in the right upper lobe (RUL) and LUL ( $P=$ .02 and .001 , respectively).

Table 6 lists 11 patients who had less than $0.10 \mathrm{~L}_{\text {of }} \mathrm{FEV}_{1}$ in the remaining lobe. Of these, 3 patients (Nos. 8, 10, and 11) had undergone basal segmentectomy, and another 3 patients (Nos. 5, 6, and 7) had undergone the left upper division segmentectomy.

\section{DISCUSSION}

The present study clarified the following points: (1) virtual lobectomy showed significant decrease of $\mathrm{FEV}_{1}$ com-

TABLE 4. Forced expiratory volume in 1 second of the left upper lobe before and after upper division segmentectomy or lingular segmentectomy

\begin{tabular}{lcccc}
\hline \multirow{2}{*}{$\begin{array}{c}\text { Site of } \\
\text { segmentectomy }\end{array}$} & $\begin{array}{c}\text { No. of } \\
\text { patients }\end{array}$ & Before & After & Before/after \\
\cline { 3 - 4 } & $\mathbf{\%})$ \\
\hline Upper division & 8 & $0.63 \pm 0.21$ & $0.14 \pm 0.11$ & $21 \pm 11$ \\
Lingular & 7 & $0.56 \pm 0.22$ & $0.21 \pm 0.11$ & $35 \pm 12$ \\
\hline
\end{tabular}

$F E V_{l}$, Forced expiratory volume in 1 second; $L U L$, left upper lobe. Upper division: apical posterior $(S 1+2)$ and apical anterior (S3). Lingular: superior lingular (S4) and inferior lingular (S5).
TABLE 5. Forced expiratory volume in 1 second of the object lobe before and after segmentectomy

\begin{tabular}{|c|c|c|c|c|c|}
\hline \multirow[b]{2}{*}{ Lobe } & \multirow[b]{2}{*}{$\begin{array}{c}\text { No. of } \\
\text { patients } \\
\end{array}$} & \multirow{2}{*}{$\begin{array}{c}\text { No. of } \\
\text { resected } \\
\text { segments }\end{array}$} & \multicolumn{2}{|c|}{ Mean $\mathrm{FEV}_{1}$ of the lobe (L) } & \multirow[b]{2}{*}{$\begin{array}{c}\text { After/before } \\
(\%)\end{array}$} \\
\hline & & & Before & After & \\
\hline RUL & 9 & $1.1 \pm 0.2$ & $0.54 \pm 0.16$ & $0.18 \pm 0.09$ & $34 \pm 13$ \\
\hline RLL & 16 & $1.6 \pm 1.1$ & $0.49 \pm 0.22$ & $0.30 \pm 0.19$ & $61 \pm 30$ \\
\hline LUL & 22 & $1.7 \pm 0.5$ & $0.61 \pm 0.19$ & $0.20 \pm 0.11$ & $32 \pm 14$ \\
\hline LLL & 9 & $1.9 \pm 0.6$ & $0.28 \pm 0.09$ & $0.11 \pm 0.08$ & $38 \pm 20$ \\
\hline
\end{tabular}

pared with segmentectomy; (2) the $\mathrm{FEV}_{1}$ of each lobe after segmentectomy remained $0.21 \mathrm{~L}$ in the mean value, which could contribute to the preservation of postoperative pulmonary function; (3) although segmentectomy with the resection of one or two segments could preserve $\mathrm{FEV}_{1}$ of each lobe absolutely, the resection of more than three segments could not; and (4) although the lingular segmentectomy could preserve $\mathrm{FEV}_{1}$ of the LUL absolutely, the upper division segmentectomy could not.

$\mathrm{FEV}_{1}$ values after virtual lobectomy in the present study were calculated by perfusion SPECT/CT but were not actual values. However, Ohno and associates ${ }^{10}$ showed highly significant correlation of pulmonary function after lobectomy between the actual value and the value calculated by perfusion SPECT/CT. Because the perfusion SPECT/CT can count the RI of each lobe accurately, we believe that it can predict postoperative pulmonary function after lobectomy with significant accuracy. However, even by using SPECT/CT, postoperative pulmonary function after segmentectomy might be hard to predict, because CT cannot clearly identify the border of the segments within a lobe.

TABLE 6. Characteristics of patients with less than $0.10 \mathrm{~L}$ of forced expiratory volume in 1 second in the remaining lobe

\begin{tabular}{cccllcc}
\hline & & & & & \multicolumn{2}{c}{ FEV $_{\mathbf{1}}$ of the lobe (L) } \\
\cline { 6 - 7 } Case & Sex & Age (y) & Lobe & Resected segments & Before & After \\
\hline 1 & F & 81 & LLL & S8 & 0.10 & 0.03 \\
2 & F & 75 & LUL & S4, 5 & 0.19 & 0.05 \\
3 & F & 59 & LLL & S9, 10 & 0.34 & 0.05 \\
4 & M & 69 & LLL & S9, 10 & 0.19 & 0.05 \\
5 & M & 80 & LUL & S1+2, 3 & 0.49 & 0.06 \\
6 & F & 70 & LUL & S1+2, 3 & 0.27 & 0.06 \\
7 & M & 70 & LUL & S1+2, 3 & 0.82 & 0.07 \\
8 & F & 81 & LLL & S8, 9, 10 & 0.24 & 0.03 \\
9 & M & 64 & RUL & S3 & 0.50 & 0.03 \\
10 & F & 80 & RLL & S7, 8, 9, 10 & 0.15 & 0.01 \\
11 & F & 70 & RLL & S7, 8, 9, 10 & 0.45 & 0.07 \\
\hline
\end{tabular}

$S$, Segment; $L U L$, left upper lobe; $L L L$, left lower lobe; $R U L$, right upper lobe; $R L L$, right lower lobe. Right upper lobe: $S 1$, apical; $S 2$, anterior; $S 3$, posterior. Right lower lobe: $S 6$, apical; $S 7$, medial; $S 8$, anterior; $S 9$, lateral; $S 10$, posterior. Left upper lobe: $S 1+2$, apical posterior; $S 3$, apical anterior; $S 4$, superior lingular; $S 5$, inferior lingular. Left lower lobe: S6: apical; S8: anterior; S9: lateral; S10: posterior. 
The present study shows that although the segmentectomy with the resection of one or two segments could preserve $\mathrm{FEV}_{1}$ of the remaining lobe absolutely, that with the resection of more than three segments could preserve only $0.06 \mathrm{~L}$ of the mean $\mathrm{FEV}_{1}$ in the remaining lobe. In addition, all 3 patients who had undergone basal segmentectomy, that is, the resection of more than three segments, had less than $0.10 \mathrm{~L}_{\text {of }} \mathrm{FEV}_{1}$ in the remaining lower lobe. Therefore, the resection of more than three segments or basal segmentectomy should be indicated only for patients with critical pulmonary function.

The present study showed that the left upper division segmentectomy resulted in significantly lower $\mathrm{FEV}_{1}$ of the remaining LUL than the lingular segmentectomy. In addition, 3 of the 8 patients who had undergone upper division segmentectomy had $\mathrm{FEV}_{1}$ less than $0.10 \mathrm{~L}$ in their remaining LUL. We suspect that the reasons for this outcome were as follows: (1) the upper division segment is usually larger than the lingular segment, because the former had 6 subsegments and the latter had only 4; and (2) the upper division segmentectomy could cause the significant decrease of the $\mathrm{FEV}_{1}$ of the lingular segment, probably because of the excessive upward bending and rotation of the lingular bronchus, similar to the occurrence of right middle lobe syndrome after right upper lobectomy. ${ }^{13,14}$

Our results showed that the $\mathrm{FEV}_{1}$ of the remaining lobe was significantly higher in RLL than in RUL and LUL, which could be caused by the following reasons: (1) the RUL has only three segments, whereas the RLL has five, which could result in a higher $\mathrm{FEV}_{1}$ of the remaining lobe in the segmentectomy of the latter; and (2) both of the apical posterior segment (S1+2) and apical anterior segment (S3) in the LUL are usually larger than each segment of the RLL, which could result in a higher $\mathrm{FEV}_{1}$ of the remaining lobe in the segmentectomy of the latter.

We conclude that segmentectomy can preserve postoperative pulmonary function absolutely compared with lobectomy, except for the resection of more than three segments or the left upper division segmentectomy. Throughout the world, several randomized trials of lobectomy versus segmentectomy in patients with small peripheral stage IA NSCLC are about to commence or are ongoing. From our data, we recommend that the patients requiring the resection of more than three segments or the left upper division segmentectomy should be excluded or examined separately for the examination of postoperative pulmonary function in these studies.

\section{References}

1. Jensik RJ, Faber LP, Milloy FJ, Monson DO. Segmental resection for lung carcinoma. J Thorac Cardiovasc Surg. 1973;66:563-72.

2,. Tsubota N, Ayabe K, Doi O, Mori T, Namikawa S, Taki T, et al. Ongoing prospective study of segmentectomy for small lung tumors. Ann Thorac Surg. 1998; 66:1787-90.

3. Okada M, Yoshikawa K, Hatta T, Tsubota N. Is segmentectomy with lymph node assessment an alternative to lobectomy for non-small cell lung cancer of $2 \mathrm{~cm}$ or smaller? Ann Thorac Surg. 2001;71:956-61.

4. Yoshikawa K, Tsubota N, Kodama K, Ayabe H, Taki T, Mori T. Prospective study of extended segmentectomy for small lung tumors: the final report. Ann Thorac Surg. 2002;73:1055-9.

5. Kodama K, Doi O, Higashiyama M, Yokouchi H. Intentional limited resection for selected patients with T1 N0 M0 non-small cell lung cancer. J Thorac Cardiovasc Surg. 1997; 114:347-53.

6. Ginsberg RH, Rubinstein LV, Lung Cancer Study Group. Randomized trial of lobectomy versus limited resection for T1N0 non-small cell lung cancer. Ann Thorac Surg. 1995;60:615-23.

7. Harada H, Okada M, Sakamoto T, Matsuoka H, Tsubota N. Functional advantage after radical segmentectomy versus lobectomy for lung cancer. Ann Thorac Surg. 2005;80:2041-5.

8. Keenan RJ, Landreneau RJ, Maley RH, Singh D, Macherey R, Bartley S, et al. Segmentectomy resection spares pulmonary function in patients with stage I lung cancer. Ann Thorac Surg. 2004;78:228-33.

9. Takizawa T, Haga M, Yagi N, Terashima M, Uehara H, Yokoyama A, et al. Pulmonary function after segmentectomy for small peripheral carcinoma of the lung. J Thorac Cardiovasc Surg. 1999;118:536-41.

10. Ohno Y, Koyama H, Takenaka D, Nogami M, Kotani Y, Nishimura Y, et al. Coregistered ventilation and perfusion SPECT using Krypton- $81 \mathrm{~m}$ and Tc- $99 \mathrm{~m}$ labeled macroaggregated albumin with multislice CT: utility for prediction of postoperative lung function in non-small cell lung cancer patients. Acad Radiol. 2007; $14: 830-8$.

11. Nomori H, Ikeda K, Mori T, Kobayashi H, Iwatani K, Kawanaka K, et al. Sentinel node navigation segmentectomy for clinical stage IA non-small cell lung cancer. J Thorac Cardiovasc Surg. 2007;133:780-5.

12. American Thoracic Society. Standardization of spirometry-1987 update. Am Rev Respir Dis. 1987;136:1285-98.

13. Irani B, Miller JE, Linberg E, Attar S. Use of radiopaque markings of middle lobe (or lingual) following upper resectional surgery. Ann Thorac Surg. 1968;5:1-7.

14. Nonaka M, Kadokura M, Tanio N, Yamamoto S, Kataoka D, Inoue K, et al Changes in lung lobar volume and bronchial deformity after right upper lobectomy. Surg Today. 1998;28:285-8. 